\title{
A pilot study on self-perceived need for management training among medical students in Latvia
}

\author{
Juris Barzdins ${ }^{1}$, Atis Barzdins ${ }^{2}$ \\ ${ }^{1}$ Centre for Health Management and Informatics, Faculty of Medicine, University of Latvia, Latvia \\ ${ }^{2}$ Seattle Cancer Treatment and Wellness Center, Cancer Treatment Centers of America, USA
}

Correspondence: Juris Barzdins, Centre for Health Management and Informatics, Faculty of Medicine, University of Latvia, Sarlotes 1a, Riga, LV 1001, Latvia. Email: juris.barzdins@lu.lv

\begin{abstract}
Objectives: To assess the self-perceived need and preferred format for educational intervention among Latvian medical students in fostering the increasing demanding of management-related competences for healthcare professionals. Methods: A cross sectional study design was used to assess student-perceived deficiencies and the need for knowledge and skills in 10 different domains of activity. All medical students from one of the two major Latvian universities were invited to participate in this survey. The knowledge gap between perceived deficiency and actual need for training in specific domains was calculated. Possible correlations between a total gap of knowledge and selected demographic parameters were identified.
\end{abstract}

Results: The response rate to this web-based questionnaire was 101/458 (22\%). The most evident gaps were reported in the domains of Management of Legal Issues in Health Care
(47\%), followed by the domains of National Healthcare System (37\%) and Management of Safety and Quality (37\%). The knowledge gap was wider among students with a higher degree of perceived competition their chosen speciality $(\mathrm{R}=0.25, \mathrm{p}=0.011)$ and with a preference to work in private clinic $(\mathrm{R}=0.26, \mathrm{p}=0.009)$, but it narrowed with advanced degree of studies $(\mathrm{R}=-0.27, \mathrm{p}=0.006)$.

Conclusions: This pilot study demonstrates that medical students recognise the necessity for additional training in management. It also highlights those domains of managerial skills and knowledge in which the students have observed the most notable existing deficiencies. These gaps and resultant issues should be addressed in the development studies programmes.

Keywords: Curriculum development, knowledge gap, management training, physicians' leadership, educational intervention

\section{Introduction}

The ever-increasing capabilities of medical science inevitably create new challenges for healthcare systems. In recent decades medical breakthroughs have not only brought about increased longevity and improved quality of life, but have also led to significant changes in healthcare system management. While the increasingly narrow specialisation of medical professionals has been essential for improvements such as the development of in-depth expertise and the application of sophisticated technologies, this progress has led to its own problems in the form of the growing complexity of patient care processes, and, inevitably, increased costs. In the development of predominant medical conditions, the contribution of unhealthy lifestyle and the aging of the population are often mentioned as the key factors that influence the demand for health services and increase their cost. Recent studies, however, confirm that demographic changes account only for a fraction of the increase in health care costs. ${ }^{1}$ The extensive use of new and costly technologies (diagnostics, treatment schemes, medical equipment, and pharmaceuticals) has increasingly been identified as the most prominent single driver of the increase in healthcare costs. ${ }^{2}$ The quest for better ways to address cost growth without unreasonably reducing access to new and needed services is a significant challenge for many countries. ${ }^{3}$ Consequently, the pressure on practising healthcare professionals is not only to seek the introduction of new technologies designed for direct improvement of patient outcomes, but also to identify circumstances and 
technologies that would achieve these improvements in a more affordable manner. Health care professionals are increasingly asked to apply lessons learned from management practices in other spheres of the economy toward the development of a more efficient patient care process. This demand is particularly evident in larger enterprises such as public hospitals where, as a result of the high cost of inpatient services, restructuring will necessarily dictate the provision of more services in cost-effective out-patient settings. $^{4}$

In controlling the resources of the enterprise, managers often have very few options available that wouldn't inhibit the professional autonomy of the physicians. ${ }^{5}$ Under such conditions neither the physicians nor managers can really be satisfied. Physicians are limited in their ability to make independent clinical decisions with the best interests of patients in mind, while managers frequently succumb to the social pressure and veto power of the eminently recognised medical professionals, a situation that allows for reforms only as far as compromise permits. This situation is perhaps the primary (but often unstated) reason for the general observation that qualitative leadership in the healthcare industry lags behind that in other industries by about 10-15 years. ${ }^{6}$ As a result, unlike in other spheres of the economy, innovation and new technologies in health care generally have led to increasing cost of services, and have not offered savings or increased access. The alignment of providers and managers toward the same set of priorities, and their ability to generate and exchange ideas effectively, will be needed to resolve this fundamental obstacle in developing a new model of value-based, personalized, and affordable health care.

\section{Rationale for the current study}

In the context of the evident non-sustainability of previous and existing medico-economic practices, we need to prepare for a paradigm shift with regard to those competences which future physicians will need to possess upon completion of their formal professional education. A professional training that is based upon an individualistic orientation does not prepare physicians to function successfully as members of large and complex organisations. ${ }^{7}$ In comparing and summarising the various competency models that have been created by different national medical professional organisations, one can well observe that in addition to the technical and/or purely professional and clinical competences, an increasing importance is being given to physicians' ability to understand the context and essence of transformation processes in health care and their ability to manage or even to lead changes as may be required. ${ }^{8-13}$

However, according to a recent systematic review of published reports, relatively little emphasis continues to be given to leadership and management education in the various medical curricula even though medical students do recognise a need to develop professional leadership and management competences. ${ }^{14}$ A review and analysis of several European medical graduate programmes has clearly revealed insufficient training for this competency in most curricula. For example, in Latvia, only one of the two major universities offers, as an elective subject, a course for the development of managerial competences. ${ }^{15}$ At the same time, there has been growing support for the embedding of leadership and management learning outcomes into professional frameworks for students and qualified clinicians ${ }^{16,17}$ and for the implementation of leadership development programmes as a standard part of the curriculum in medical schools. ${ }^{18}$

In view of the fact that the whole concept of management competency training for physicians is still evolving, it is not at all surprising that such training is not yet universally required. In the search for an appropriate standard for the content, form, and timing of such courses, it is important to understand the perception of this issue by medical students themselves. Several studies have already documented that medicine residents as well as those already working in medicine wish they had received more training in the managerial knowledge and skills-related topics. ${ }^{19-23}$ However, we were able to find only a few studies and case reports that accurately describe the early introduction and development of leadership and management competency training as a component of professional medical education. Two publications described a positive experience with the management training and leadership curriculum as implemented in several medical schools in the United States. ${ }^{24,25}$ Another study compared the perceptions on management education of British and Portuguese medical students, hospital managers, and clinical directors. ${ }^{26}$ In this study, the participants described management education as an integral part of the undergraduate medical educational process and identified topics that ought to be covered, including people management, structure of the national health services system, the leadership role of doctors, and costs and resources management. A study performed in the United States by Varkey et al. investigated the student and faculty attitudes toward the implementation of leadership studies in the curriculum. ${ }^{27}$ In this study, the topics of communication, conflict resolution, time management, negotiation, delegation, teamwork, and community service were identified by the participants as the key skills and necessary outcomes of leadership training. The survey questions of our own study enquired into: (1) Whether medical students perceive that they have knowledge gaps in managementrelated areas, (2) what medical students consider is important to know about management knowledge and skills, (3) whether these views were influenced by their year of training or career aspirations, and (4) what types of educational interventions they would prefer, and the stage at which these should take place in their training. 


\section{Methods}

\section{Study design and data collection}

The subjects of this study were students at one of the two major universities in Latvia that provide study programmes in medicine. A web-based questionnaire was developed in collaboration with a group of educators and pre-tested by eight medical students. Their feedback was used to revise the questionnaire. The finalised questionnaire consisted of two sections. The first section assessed the representative characteristics of the respondents - their current year of study, preferred settings for future professional activities, self-assessment of current leadership abilities, and degree of perceived competition in their chosen specialty. The second section consisted of paired questions examining studentperceived deficiencies and needs for conceptual management related knowledge and skills in ten domains.

In order to allow for a broader interpretation of the respective areas of knowledge and skills, respondents were not provided with any extensive definitions of the proposed domains. The self-assessed perception in all domains was measured with a 7 point Likert-type scale that gauged respondents' proximity to one of the two opposing statements. There was an open-ended section at the end of the questionnaire for comments on any additional areas of conceptual knowledge and skills that should be covered during their university schooling.

An informed consent statement for distribution of the questionnaire was provided by the dean of each department. The university research ethics representative confirmed that according to Latvian law no ethical approval was needed for a study of this kind. ${ }^{28}$ Engaging the 'Webanketa.com' application, an invitation letter explaining the purpose of the survey together with a link to the questionnaire was sent to all 458 medical students of the university by e-mail for voluntary and anonymous completion. The potential respondents were allowed one month to reply to the questionnaire. During this time period they received two reminder notices.

\section{Data analysis}

The data received were analysed using the Statistical Package for the Social Sciences (SPSS Version 19). Internal consistency and reliability of the questionnaire was tested using Cronbach's alpha. Data analysis included Simple Descriptive Statistics, which were computed for each of the items on the questionnaire. To calculate the gap between the respondents' perceived current level of knowledge or skill and the importance of acquisition of the same, we replicated the methodology employed in a similar study on post-graduate trainees in Canada. ${ }^{19}$ In the Canadian study, Stergiopoulos et al. used the paired-question principle; the gap in a specific domain was thus defined as the difference between the reported scores of perceived current knowledge or skill and the reported scores of perceived importance in acquiring the same. We used the same definition of knowledge gap and a similar method for representation of the data. The mean knowledge gap in each of the separate domains and the summary mean gap for all of the respondents were both calculated. For the correlation and comparison tests, a threshold of statistical significance was fixed at 0.05 . Chi-squared analyses were performed to determine the degree of 'representativeness' of the sample to the population with regard to the year of training. A hypothesis was proposed that respondent characteristics such as current year of studies, preferred setting of future professional activities, self-assessment of leadership abilities, and presence of perceived competition in the chosen specialty might influence student knowledge and skill gaps. A bivariate correlation analysis was used to determine any possible correlations.

\section{Results}

Of the 458 medical students contacted, 101 completed the web-based survey (a response rate of $22.05 \%$ ). An estimated $97 \%$ of these respondents reported a gap between the perceived deficiency and need for training in the examined domain. A representative distribution of the questioned subjects and survey respondents according to their training year is detailed in Table 1.

Table 1. Distribution of surveyed population and respondents according to year of training

\begin{tabular}{cccccc}
\hline \multirow{2}{*}{ Year of training } & $\begin{array}{c}\text { Surveyed } \\
\text { population }\end{array}$ & & \multicolumn{2}{c}{$\begin{array}{c}\text { Survey } \\
\text { respondents }\end{array}$} & $\%$ \\
\cline { 2 - 2 } \cline { 5 - 5 } & $\mathrm{N}=458$ & & $\mathrm{~N}=101$ & \\
\hline $1^{*}$ & 149 & 33 & 17 & 17 \\
2 & 97 & 21 & 17 & 17 \\
3 & 64 & 14 & 18 & 18 \\
4 & 46 & 10 & 14 & 14 \\
5 & 52 & 11 & 15 & 15 \\
$6^{*}$ & 50 & 11 & 20 & 20 \\
\hline
\end{tabular}

${ }^{*} p<0.01$, significant differences in the representation between respondents and surveyed population have been identified by chi-squared analyses.

The significant differences in the representation of respondents and of the surveyed population indicate some underrepresentation of the undergraduate year one and an overrepresentation of year six. While $6.6 \%$ of respondents had not yet determined their employment preferences for the future, a large proportion of questionnaire respondents envisioned working in a state or municipal hospital (27.0\%) and/or in a privately owned specialty clinic/practice (21.3\%). Only a minority (3.8\%) planned to become general practitioners, $4.3 \%$ had entertained plans to work in other healthcare related jobs, and $0.5 \%$ were prepared to seek employment not directly related to healthcare. The preferred location for employment of $18.0 \%$ of respondents was the capital city, with $6.2 \%$ opting for other locations in the country, $12.3 \%$ looking forward to opportunities abroad, and the remainder undecided. 
Respondent perceptions of their knowledge and skill levels in individual domains (and their perception of the importance of furthering their knowledge in each of the domains) are summarised in Table 2.

Table 2. Student perception of managerial knowledge and skill domains ( $N=101$, gap scale from 0 to 7$)$

\begin{tabular}{|c|c|c|c|c|c|c|c|}
\hline \multirow[t]{2}{*}{ Knowledge domain } & \multicolumn{2}{|c|}{$\begin{array}{l}\text { Perceived } \\
\text { level of } \\
\text { knowledge }\end{array}$} & \multicolumn{2}{|c|}{$\begin{array}{l}\text { Perceived } \\
\text { level of } \\
\text { importance }\end{array}$} & \multicolumn{2}{|c|}{$\begin{array}{l}\text { Knowledge } \\
\text { /importance } \\
\text { gap }\end{array}$} & \multirow{2}{*}{$\begin{array}{l}\text { Gap } \\
(\%)\end{array}$} \\
\hline & $\begin{array}{l}\text { Mean } \\
\text { score }\end{array}$ & SD & $\begin{array}{l}\text { Mean } \\
\text { score }\end{array}$ & SD & $\begin{array}{c}\text { Mean } \\
\text { gap }\end{array}$ & SD & \\
\hline $\begin{array}{l}\text { Effective communication } \\
\text { in teams }\end{array}$ & 5.2 & 1.7 & 6.1 & 1.8 & 1.0 & 1.1 & 14.9 \\
\hline $\begin{array}{l}\text { Effective communication } \\
\text { with patients }\end{array}$ & 4.8 & 1.9 & 6.3 & 1.8 & 1.5 & 1.5 & 22.0 \\
\hline $\begin{array}{l}\text { National healthcare } \\
\text { system }\end{array}$ & 3.6 & 1.3 & 5.9 & 1.4 & 2.3 & 1.9 & 32.7 \\
\hline $\begin{array}{l}\text { Safety and quality } \\
\text { management }\end{array}$ & 3.5 & 1.7 & 6.1 & 1.8 & 2.6 & 1.8 & 37.3 \\
\hline $\begin{array}{l}\text { Physician's role in the } \\
\text { management of health } \\
\text { care resources }\end{array}$ & 3.3 & 1.6 & 5.1 & 1.8 & 1.9 & 1.8 & 26.6 \\
\hline $\begin{array}{l}\text { European healthcare } \\
\text { systems }\end{array}$ & 2.8 & 1.2 & 5.4 & 1.2 & 2.6 & 1.8 & 37.0 \\
\hline Healthcare economics & 2.8 & 1.5 & 4.3 & 1.7 & 1.5 & 1.7 & 21.1 \\
\hline $\begin{array}{l}\text { Common management } \\
\text { skills }\end{array}$ & 2.8 & 1.5 & 5.2 & 1.4 & 2.4 & 2.0 & 33.9 \\
\hline $\begin{array}{l}\text { Functioning of the } \\
\text { hospital }\end{array}$ & 2.7 & 1.5 & 4.9 & 2.0 & 2.1 & 2.0 & 30.4 \\
\hline $\begin{array}{l}\text { Management of legal } \\
\text { issues in healthcare }\end{array}$ & 2.2 & 1.3 & 5.5 & 1.8 & 3.3 & 1.8 & 47.0 \\
\hline
\end{tabular}

The highest scores for perceived knowledge and skills were for Effective Communication in Teams and Effective Communication with Patients. These two domains, along with Safety and Quality Management, were those with the highest importance. Among the other areas of highly perceived knowledge and skills were National Health Care System and the National and European Health Care System. The lowest scores for perceived current knowledge or skills were for Management of Legal Issues in Health Care and Functioning of the Hospital. Among all of the domains in question, the areas in which respondents perceived the least need for furthering knowledge or skills were Health Care Economics and Functioning of the Hospital. Nevertheless, the calculated knowledge gaps were significant in all domains. The widest gap between perceived level of current knowledge and perceived level of importance (thus implicitly indicating the greatest need for additional educational intervention) was for Management of Legal Issues in Health Care $(47.0 \%)$. The smallest gap (and therefore the domain in which students indirectly expressed less need for additional training) was for Effective Communication in Teams (14.9\%). A visualisation of the ranked gaps is presented in Figure 1.

The mean knowledge gap for respondents in all of the domains was 2.1 (SD 1.13) or $30.1 \%$ from 7 on the Likert scale. As there was a set hypothesis that respondent characteristics, such as current year of studies, preferred setting of future professional activities, self-assessment of own leadership abilities, and presence of perceived competition in chosen speciality might influence student knowledge and skill gaps, a simple bivariate correlation analysis was performed. The value of knowledge gap had a negative significant correlation with the greater number of the years of study and a positive correlation with the presence of perceived competition in the profession and preference to work in a private clinic. The results of the bivariate correlation of selected parameters to the knowledge gap are summarised in Table 3.

Table 3. Bivariate correlation to knowledge gap $(\mathrm{N}=101$, gap scale from 0 to 7 )

\begin{tabular}{lcc}
\hline Selected parameters to the knowledge gap & $\begin{array}{c}\text { Pearson } \\
\text { Correlation }\end{array}$ & $\begin{array}{c}\text { Significance } \\
\text { (2-tailed) }\end{array}$ \\
\hline Prefers to work in private clinic & $0.259^{* *}$ & 0.009 \\
Advanced degree of studies & $-0.269^{* *}$ & 0.006 \\
$\begin{array}{l}\text { Higher level of self-reported personal leader- } \\
\text { ship trait }\end{array}$ & 0.127 & 0.207 \\
$\begin{array}{l}\text { Higher degree of perceived competition in } \\
\text { profession }\end{array}$ & $0.252^{*}$ & 0.011 \\
\hline
\end{tabular}

"Correlation is significant at the 0.01 level (2-tailed); "Correlation is significant at the 0.05 level (2-tailed).

In the section dealing with preferred training settings, the opinion on whether training should be mandatory or elective varied significantly among domains. Safety and Quality Management in Health Care, Effective Communication with Patients, and Management of Legal Issues and Healthcare were three domains considered most likely to require mandatory training. By contrast, Health Care Economics, Common Management Skills, and European Health Care Systems were most likely to receive an "elective” training preference (Figure 2).

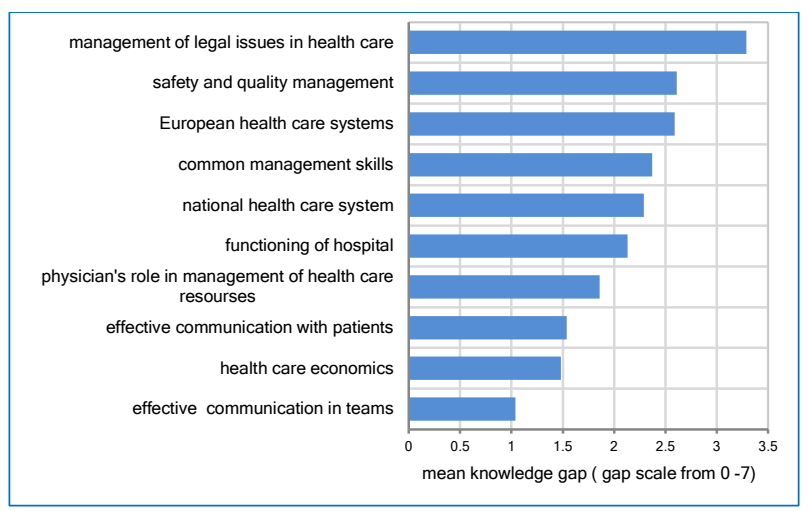

Figure1. Knowledge gaps in selected domains $(\mathrm{N}=101)$

As for the question of preferred timing for training, there was a wide variation of respondent preferences. The domains most preferred to be taught during the first years of study were Health Care Economics and Effective Communication with Patients and Teams. The domains mostly preferred to be taught later-during postgraduate studies, or even in the workplace-were Functioning of the Hospital, Physician's Role in Management of Health Care Resources, and Common Management Skills. Preferences for the year of interventive training in all of the domains are summarised in Figure 3. 


\section{Discussion}

The primary objective of medical training has always been to develop expertise in diagnosing and managing disease. Medical school training has traditionally placed little emphasis on the development of the cognitive skills and abilities that are needed to perceive the organisation as a whole system of complex interrelationships. This has resulted in physicians being forced to learn many such skills-e.g., fulfilling leadership roles in healthcare teams, making bedside decisions on the use of available resources and, in fact, ultimately being accountable for the main business processes within the organisation- "on-the-job."

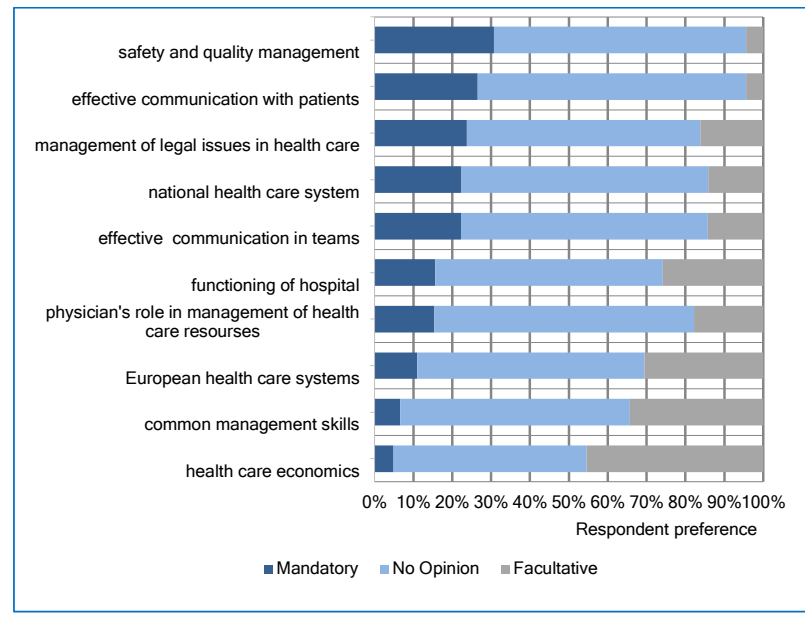

Figure 2. Respondent preference for type of educational intervention in selected domains

In accord with what has previously been reported by other studies on residents and those already working in medicine ${ }^{19-23}$, this study has demonstrated that medical students do recognise the importance of conceptual, managementrelated competences and are prepared to undertake additional training in order to succeed in the furthering of their professional careers. This is an important finding because it is known that in order to achieve competency in management-related areas, theoretical knowledge and even certain skills need to be taught early in the educational process so as to allow for the development of a mind-set based upon appropriate values. Physicians' desire to utilise existing managerial knowledge and skills could lead to their greater understanding of and participation in the transformation of practice currently taking place in the profession. With these considerations in mind, the findings of this study add conclusive arguments for the need for early educational intervention to promote further development of real conceptual competencies.

Although the management-related areas under investigation here are not exactly the same as those investigated in other studies, this study allows aspects of the population of medical students to be analysed and compared to the results of studies on postgraduate medical residents. For example, in comparison with the results of the Canadian study on medical residents, ${ }^{19}$ it is evident that the training gaps in most areas of our study appear to be wider. This difference may well be indicative of the fact that over the course of training some management-related areas are covered within the existing curriculum. Additional evidence for this is the fact that in the present study the overall knowledge gap was reported to be significantly wider for students in the first three years of training than for those approaching graduation.

Despite all of these significant observations, there are several limitations to the present study. First of all, we only examined the existing situation in one particular Latvian university. We also concede that differences in study programme curricula might well influence respondent opinions on perceived gaps in training, especially for later study years. Another possible limitation in interpreting results is associated with response rate. Even if the number of respondents was considered sufficient for further analysis, the rate of response to the e-mailed invitation to participate in the web-based survey was moderate. Nevertheless, although the student response rate for online evaluations is lower in general, there are studies that confirm that evaluation scoring patterns and responses may be similar for both online and paper-based surveys. ${ }^{29}$ Another possible limitation to this study is the fact that we did not seek to identify or differentiate respondent gender. We do agree that gender is an important factor and that there would likely be a difference in various responses and participation rates between male and female students. Nevertheless, we are of the opinion that, from a practical implementation point of view this gender-difference characteristic has a limited impact on the overall design of study programmes.

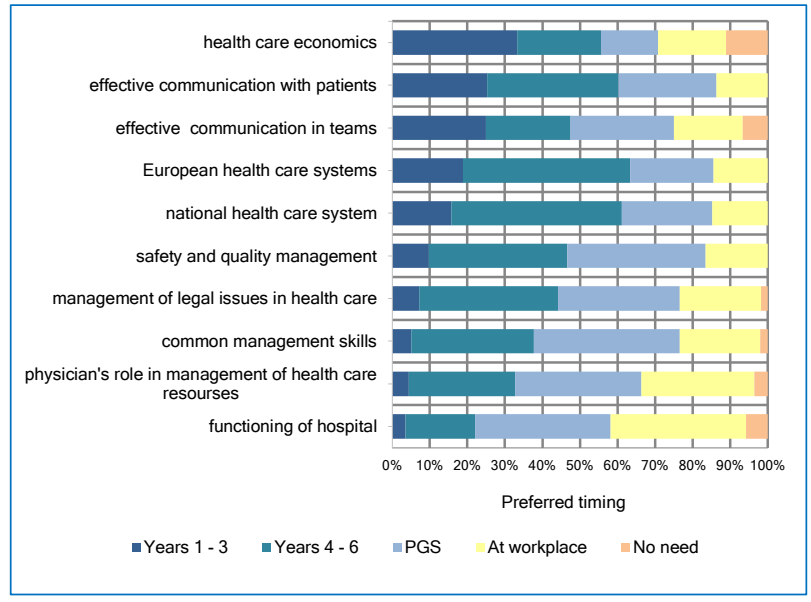

Figure 3. Preferred timing of educational intervention by domain

With regard to the question of preferred additional/interventional training settings and timing, no individual interpretation of the results of this study could be straightforward because of the wide variations between students and domains. Another limitation lies in the fact that more than half of the respondents were unable to indicate whether such additional/interventional training should be 
mandatory or optional. In fact, there were no domains in which the need for mandatory inclusion of relevant additional/interventional training in the study programme exceeded 30\%. For the Common Management Skills and Health Economics domains this proportion was as low as $6.6 \%$ and $4.8 \%$, respectively. This finding suggests that a simple didactic approach to the teaching of Management and Economics might not be easily accepted by medical students. It points to a need for the maximum integration of such training across all years of study and for the need to find ways to address management aspects while teaching existing courses. However, while an integrated approach is recommended by other authors ${ }^{30}$, it is our opinion that such a bedside training approach will be difficult to realise if we take into account the competences of present-day clinical teachers themselves and the cross-functional dimensions of management and leadership-related issues in healthcare. Another limitation to any direct transfer of study findings on educational intervention for existing medical studies programmes is suggested by the fact that our evaluation only reflected student-perceived gaps between existing levels of knowledge/skills. The findings of this study confirm that undergraduate students support a re-shaping of their existing study programmes. However, the changes students support may not necessarily reflect the needs or educational gaps identified by experts in teaching, clinicians in practice, and/or healthcare managers in the field. Another dimension that has not been addressed by this study is the possibility for educational interventions to promote physicians' ability to recognize nurses and allied health professionals in their managerial roles within health care organizations.

Educational intervention for the development of management skills as part of the traditional approach in the training of physicians remains a challenge. There is an obvious need for further research to find the most appropriate ways in which to foster the wider range of conceptual competences necessary for the modern-day physician. Meanwhile, it is also becoming evident that leadership at the highest level needs to start applying the gathered evidence to set the course of change in professional medical education in order to respond to the emerging needs of our healthcare systems.

\section{Conflict of Interest}

The authors declare that they have no conflict of interest.

\section{References}

1. Dormont B, Grignon M. Health expenditure growth: reassessing the threat of ageing. Health Economics. 2006;963:947-63.

2. Lubitz J. Health, technology, and medical care spending. Health Affairs. 2005;24 Suppl. 2:W5R81-R85.

3. Marmor T, Oberlander J, White J. The Obama administration's options for health care cost control: hope versus reality. Annals of Internal Medicine. 2009;150(7):485-9.
4. Mckee M, Healy J. The evolution of hospital systems. In: Mckee M, Healy J, editors. Hospitals in a changing Europe. European Observatory. Buckingham: Open University Press; 2002. page 14-36.

5. Kippist L, Fitzgerald A. Organisational professional conflict and hybrid clinician managers: the effects of dual roles in Australian health care organisations. Journal of Health Organisation and Management. 2009;23 (6):642-55.

6. Mcalearney A. Leadership development in healthcare: a qualitative study. Journal of Organizational Behavior. 2006;982(7):967-82.

7. Edwards N, Kornacki MJ, Silversin J. Unhappy doctors: what are the causes and what can be done? BMJ (Clinical research ed.) 2002; 6;324(7341):835-8.

8. Royal College of Physicians and Surgeons of Canada. The CanMEDS 2005 Physician Competency Framework [cited 7 Sep 2012]. 2005 page 1-40. Available from: http://rcpsc.medical.org/canmeds/CanMEDS2005/Can MEDS2005_e.pdf.

9. Clark J, Armit K. Leadership competency for doctors: a framework. Leadership in Health Services. 2010;23(2):115-29.

10. Calhoun JG, Dollett L, Sinioris ME, Wainio JA, Butler PW, Griffith JR, et al. Development of an interprofessional competency model for healthcare leadership. Journal of Healthcare Management. 2003;53(6):375-89.

11. McKenna MK, Gartland MP, Pugno PA. Development of physician leadership competencies: perceptions of physician leaders, physician educators and medical students. The Journal of Health Administration Education. 2004;21(3):343-54.

12. The Royal Australasian College of Medical Administrators. Medical Leadership and Management Curriculum [cited 7 Sep 2012]. 2011. Available from: http://www.racma.edu.au/index.php?option=com_docman \&task=doc_view\&gid $=1077$.

13. NHS Institute for Innovation and Improvement and Academy of Medical Royal Colleges. Medical leadership competency framework. [cited 7 Sep 2012]. 2010. Available from: http://www.institute.nhs.uk/images /documents/Medical Leadership Competency Framework 3rd ed.pdf.

14. Abbas MR, Quince T, Wood DF, Benson J. Attitudes of medical students to medical leadership and management: a systematic review to inform curriculum development. BMC Medical Education. 2011;11(1):93.

15. Barzdins J. Developing health care management skills in times of crisis: a review from the Baltic region. International Journal of Healthcare Management. 2012;5(3):129-40.

16. McKimm J, O’Sullivan H. Leadership development for clinicians: what are we trying to achieve? Clinical Teacher. 2011;8(3):181-5.

17. Swanwick T, McKimm J. Leadership development requires system-wide interventions, not just courses. Clinical Teacher. 2012;9(2):89-93.

18. O'Sullivan H, McKimm J. Medical leadership and the medical student. British Journal of Hospital Medicine. 2011;72(6):346-9.

19. Stergiopoulos V, Lieff S, Razack S, Lee a C, Maniate JM, Hyde S, et al. Canadian residents' perceived manager training needs. Medical Teacher 2010;32(11):e479-85.

20. Brouns JW, Berkenbosch L, Ploemen-Suijker FD, Heyligers I, Busari JO. Medical resident perceptions of the need for management education in the postgraduate curriculum: a preliminary study. International Journal of Medical Education. 2010;1:76-82.

21. Daugird a J, Spencer DC. The perceived need for physician management training. The Journal of Family Practice. 1990;30(3):348, 351-2.

22. Busari JO, Berkenbosch L, Brouns JW. Physicians as managers of health care delivery and the implications for postgraduate medical training: a literature review. Teaching and Learning in Medicine. 2011;23(2):186-96.

23. Sockalingam S, Stergiopoulos V, Maggi J. Residents' perceived physician-manager educational needs: a national survey of psychiatry residents. Canadian Journal of Psychiatry. Revue Canadienne de Psychiatrie. 2008;53(11):745-52.

24. Padilla PM, White JF, Bovee C, McQueen ME. An innovative, interdisciplinary healthcare entrepreneurship and innovation program for medical students. USASBE 2011 Proceedings [cited 7 Sep 2012]. 2011. page 48-61. Available from: http://usasbe.org/knowledge/proceedings/proceedingsDocs /2011/PaperID110.pdf. 
25. O'Connell MT, Pascoe JM. Undergraduate medical education for the 21st century: leadership and teamwork. Family Medicine. 2004;36 Suppl

:S51-6.

26. Martins HMG, Detmer DE, Rubery E. Perspectives on management education: an exploratory study of UK and Portuguese medical students. Medical Teacher. 2005;27(6):493-8.

27. Varkey P, Peloquin J, Reed D, Lindor K, Harris I. Leadership curriculum in undergraduate medical education: A study of student and faculty perspectives. Medical Teacher. 2009;31(3):244-50.
28. The Law on Scientific Activity [cited 7 Sep 2012]. Riga: The Saeima, Republic of Latvia; 2005. Available from: http://www.vvc.gov.lv/export/ sites/default/docs/LRTA/Likumi/Law_on_Scientific_Activity.doc.

29. Fike DS, Doyle DJ, Connelly RJ. Online vs . paper evaluations of faculty: when less is just as good. The Journal of Effective Teaching. 2010;10(2):4254.

30. Cox M, Pacala JT, Vercellotti GM, Shea JA. Health care economics, financing, organization and delivery. Family Medicine. 2004;36(January suppl):S20-S30. 